\title{
Effect of Nano Combustion Modifier on Combustion Properties of DB and CMDB-propellant
}

\author{
Zhi-Feng YUAN ${ }^{1,2, a}$, Feng-Qi ZHAO ${ }^{1, b,{ }^{*}}$, Jiao-Qiang ZHANG ${ }^{2, c}$, \\ Hong-Xu GAO ${ }^{1, d}$, Xiu-Duo SONG ${ }^{1, e}$, Yan-Jing YANG ${ }^{1, f}$, Wei ZHENG ${ }^{1, g}$, \\ Liang $\mathrm{MA}^{1, \mathrm{~h}}$ \\ ${ }^{1}$ Science and Technology on Combustion and Explosion Laboratory, Xi'an Modern Chemistry \\ Research Institute, Xi'an, 710065, China \\ ${ }^{2}$ Northwestern Polytechnical University, Xi'an, 710072, China \\ a2430837263@qq.com, bzhaofqi@163.com, czhangjq@Nwpu.edu.cn, \\ dgaohx204@163.com, ${ }^{\mathrm{e}}$ song-xd@126.com, ${ }^{\mathrm{f}} \mathrm{mseyyj@163.com,}{ }^{\mathrm{g}}$ zhei-wei035991@163.com, \\ ${ }^{\mathrm{h}}$ maliangtiantian@163.com \\ ${ }^{*}$ Corresponding author
}

Keywords: Nano Combustion Modifier, Propellant, Combustion Property, Burning Rate, Mesa Effect, Plateau Effect.

\begin{abstract}
In order to investigate the effects of several nano combustion modifiers (nm-DPT, $\mathrm{nm}-\mathrm{CB}$ and $\mathrm{nm}-\mathrm{Al}$ ) on the combustion properties of DB/Al-CMDB/RDX-CMDB propellants, the propellant samples were prepared through a solventless extrusion technique. The burning rates of propellants were measured by the strand burner method. The results showed that the nm-DPT enabled a plateau burning effect to appear for the Al-CMDB propellant in the pressure range of $8 \sim 22 \mathrm{MPa}$, and the burning rate at $10 \mathrm{MPa}$ to exceed $29 \mathrm{~mm} / \mathrm{s}$. The additional $\mathrm{nm}-\mathrm{CB}$ powder increased the burning rates of the propellant, and the propellant burning rate at 10MPa exceeded $35 \mathrm{~mm} / \mathrm{s}$. The nm-DPT enabled a plateau burning effect to appear for the RDX-CMDB propellant in the pressure range of $8 \sim 22 \mathrm{MPa}$ and a mesa effect in the pressure range of 12 22MPa, and the burning rate at $10 \mathrm{MPa}$ to exceeded $28 \mathrm{~mm} / \mathrm{s}$. The additional $\mathrm{nm}-\mathrm{CB}$ increased the burning rate of the propellant, the burning rate at $10 \mathrm{MPa}$ exceeded $30 \mathrm{~mm} / \mathrm{s}$ and the pressure exponent in the pressure of 16 22MPa was -0.10 .
\end{abstract}

\section{Introduction}

As a new kind of functional material, much attention has been paid to nanomaterials. The preparation of nano metal powder, nano metal oxide; nano metal composites and nano carbon materials were investigated. The applications of many kinds of nano materials including nano oxides in DB-propellant were reported in many literatures. And the influence of nano materials on thermal decomposition of some compositions of propellant was studied much ${ }^{[1-13]}$. But the nanometer materials enhancing the burning rate of propellant was not so much.

High burning rate propellants have great potential applications in high velocity kinetic energy missle and aerial defence missle, antitank missle and new individual weapon for soldiers .However, it is hard to exceed $30 \mathrm{~mm} / \mathrm{s}$ for the burning rate of $\mathrm{DB} / \mathrm{CMDB}$ propellants. Aiming at the need of high burning rate $\mathrm{DB} / \mathrm{CMDB}$ propellants, this paper studied the influences of some nano materials on the burning properties of DB/CMDB propellants. And it turned out that the burning rate of Al-CMDB propellant reached $35 \mathrm{~mm} / \mathrm{s}(10 \mathrm{MPa})$. The author wished this paper could provide 
technology auspice for the application of this kind of nanometer materials in DB/CMDB propellants.

\section{Experiment}

\section{Materials}

Nitrocellulose (NC, industrial pure), Nitroglycerine (NG, industrial pure), Cyclotrimethylenetrinitramine (RDX, industrial pure), the burning catalysts adopted here included $\mathrm{Pb}-\mathrm{Cu}-\mathrm{CB}$ composite and nano DPT with a diameter of 50nm. Moreover, nano $\mathrm{Al}(80 \mathrm{~nm})$ and nano carbon black (nm-CB, 50nm) were used in the experiments. Nm-DPT was shown in Fig. 1 tested by SEM (Scanning electronic microscopy).

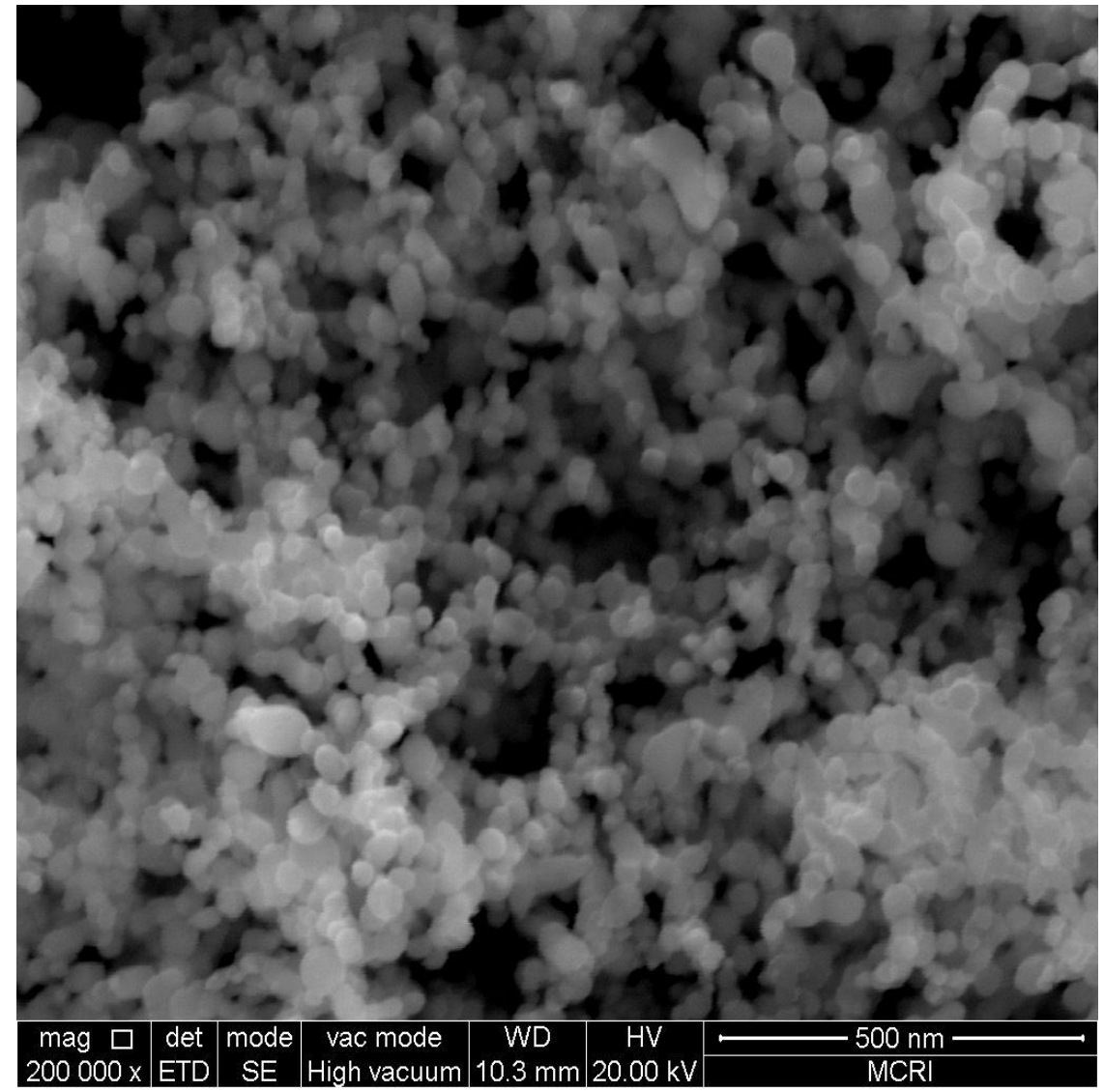

Fig.1 SEM Photograph of nm-DPT

\section{Burning Rate Test}

The burning rates were tested following the method of GJB770B-2005 706.1 "the burning rate strand burner method". The samples for test were $\varphi 5 \mathrm{~mm} \times 160 \mathrm{~mm}$ strand covered with polyvinyl alcohol, the burning rates were tested in azotes and the pressure exponent were calculated according to the relation of $\mathrm{u}=\mathrm{apn}$, where $\mathrm{u}$ was the burning rate, $\mathrm{p}$ was pressure, a was constant.

\section{Formulation Designation and Sample Preparation}

The DB/Al-CMDB/RDX-CMDB propellant formulations with or without catalysts were designed as exhibited in Table 1.

The propellant samples were prepared by solventless extrusion technology including absorbing, dehydrating, extrusion and cutting. 
Tab.1 The Formulation of Propellants

\begin{tabular}{|c|c|c|c|c|c|c|c|c|c|c|}
\hline \multirow[b]{2}{*}{ No. } & \multicolumn{10}{|c|}{$\omega / \%$} \\
\hline & $\mathrm{NC}+\mathrm{NG}$ & RDX & $\mathrm{Al}$ & $\mathrm{Pb}$ salt & $\begin{array}{c}\mathrm{Cu} \\
\text { Salt }\end{array}$ & $\mathrm{CB}$ & $\begin{array}{l}\mathrm{nm}- \\
\mathrm{DPT}\end{array}$ & nm-CB & $\mathrm{nm}-\mathrm{Al}$ & others \\
\hline 1 & 82.9 & & & 3.5 & 1.0 & 0.75 & & & & 11.85 \\
\hline 2 & 82.9 & & & 3.5 & 1.0 & 0.75 & 0.7 & & & 11.15 \\
\hline 3 & 82.9 & & & 3.5 & 1.0 & 0.75 & 0.7 & 0.3 & & 10.85 \\
\hline 4 & 80 & & & 2.5 & 2.5 & 0.3 & & & 0 & 14.7 \\
\hline 5 & 80 & & & 2.5 & 2.5 & 0.3 & & & 2 & 12.7 \\
\hline 6 & 80 & & & 2.5 & 2.5 & 0.3 & & & 5 & 9.7 \\
\hline 7 & 80 & & & 2.5 & 2.5 & 0.3 & & & 10 & 4.7 \\
\hline 8 & 82.5 & & & 3.0 & 0.5 & 0.75 & & 0 & & 13.25 \\
\hline 9 & 82.5 & & & 3.0 & 0.5 & 0.75 & & 0.3 & & 12.95 \\
\hline 10 & 82.5 & & & 3.0 & 0.5 & 0.75 & & 0.5 & & 12.75 \\
\hline 11 & 82.9 & & 5.5 & & & & & & & 11.6 \\
\hline 12 & 82.9 & & 5.5 & & & & 1.0 & & & 10.5 \\
\hline 13 & 82.9 & & 5.5 & 3.5 & 1.0 & 0.75 & & & & 5.25 \\
\hline 14 & 82.9 & & 5.5 & 3.5 & 1.0 & 0.75 & 0.7 & & & 4.55 \\
\hline 15 & 82.9 & & 5.5 & 3.5 & 1.0 & 0.75 & 0.7 & 0.3 & & 4.25 \\
\hline 16 & 63.4 & 24 & & 3.5 & 0.7 & 0.65 & & & & 7.75 \\
\hline 17 & 63.4 & 24 & & 3.5 & 0.7 & 0.65 & 0.7 & & & 7.05 \\
\hline 18 & 63.4 & 24 & & 3.5 & 0.7 & 0.65 & 0.7 & 0.3 & & 6.75 \\
\hline 19 & 63.4 & 24 & & & & & & & & 12.6 \\
\hline 20 & 63.4 & 24 & & & & & 0.7 & & & 11.9 \\
\hline 21 & 63.4 & 24 & & & & & 0.7 & 0.3 & & 11.06 \\
\hline
\end{tabular}

\section{Results and Discussion}

\section{Effect of nm-DPT, nm-CB and Common Catalyst on the Burning Properties of DB Propellants}

The DB propellants were widely adopted in many missiles. This paper dealt with the effect of $\mathrm{nm}-\mathrm{DPT}$, nm-CB and common catalyst on the burning properties of DB propellant. The results are shown in Fig.2.

As shown in Fig.2, adding nm-DPT to the DB propellant could increase the burning rate (the burning rate at $10 \mathrm{MPa}$ could be enhanced by $30 \%$ ) and reduce the pressure exponent in middle and high pressure zone (the pressure exponent in $8 \sim 22 \mathrm{MPa}$ could be reduced to -0.13). Adding nm-DPT to the DB propellant could result in high burning rate and low pressure exponent, which are very favorable for applications of DB propellants.

$\mathrm{Nm}-\mathrm{CB}$ could increase the burning rate under the high pressure $(12 \sim 22 \mathrm{MPa})$ on the basis of adding nm-DPT. For example, the burning rate reached $40 \mathrm{~mm} / \mathrm{s}$ under $14 \mathrm{MPa}$, and exceeded $44 \mathrm{~mm} / \mathrm{s}$ when the pressure increased to 22MPa.Meanwhile, the pressure exponent between $8 \sim 22 \mathrm{MPa}$ increased to 0.35 because the burning rates at high pressure zone were enhanced. 


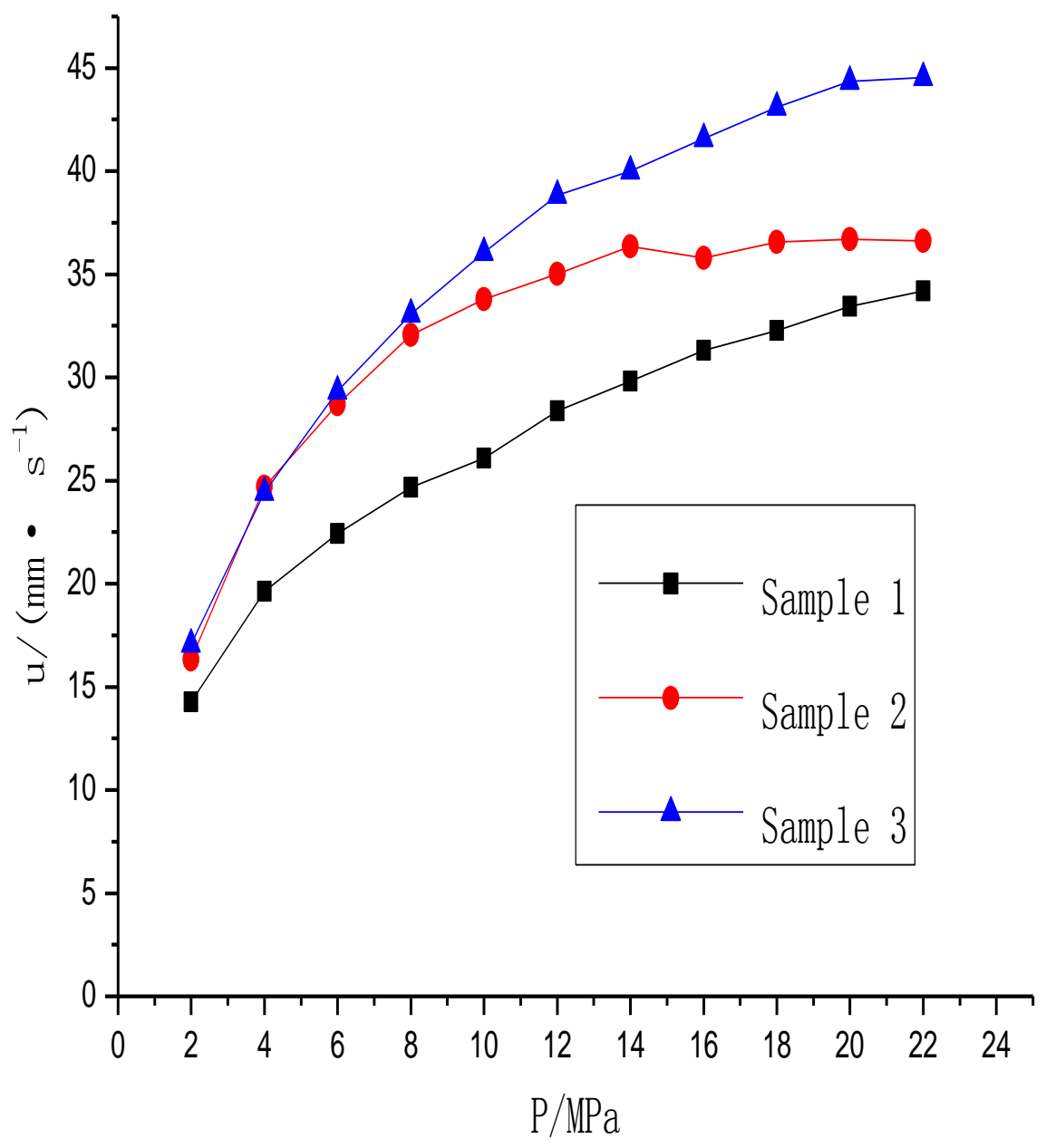

Fig.2 Effect of nm-DPT, nm-CB and Common Catalyst on Combustion Properties of DB Propellant

Nm-DPT could increase the burning rate and reduce the pressure exponent at high pressures remarkably even when other catalyst were also added to the propellants which resulted a low content of nm-DPT of lower than $1 \%$.Obviously,nm-DPT is a promising assistant catalyst.

\section{Effect of nm-Al and nm-CB to the Combustion Properties on DB Propellants}

There are many reports on application of $\mathrm{nm}-\mathrm{Al}$ in propellants ${ }^{[14-16]}$, but only a few job dealt with the effect of $\mathrm{nm}-\mathrm{Al}$ on the combustion property of DB propellant, especially the effects of the content of $\mathrm{nm}-\mathrm{Al}$ on combustion property. Similarly, there was only a few works on the application of $\mathrm{nm}-\mathrm{CB}$ in $\mathrm{DB}$ propellants. In this work, the effects of $\mathrm{nm}-\mathrm{Al}$ and $\mathrm{nm}-\mathrm{CB}$ on propellant's combustion properties were as shown in Fig.3.

As shown in Fig.3, adding nm-Al could reduce the burning rates of propellant much in middle or low pressure zone, but results in only a little change for burning rates in high pressure zone, so the pressure exponent was enhanced significantly. With the increase in content of $\mathrm{nm}-\mathrm{Al}$, the burning rate reduced markedly but the pressure exponent increased gradually. The burning rate of DB propellant containing common catalyst would increase a little and the pressure exponent would not change evidently for adding nm-CB into the propellant. With the increase in content of nm-CB, the burning rate increased a little but the pressure exponent did not change. 


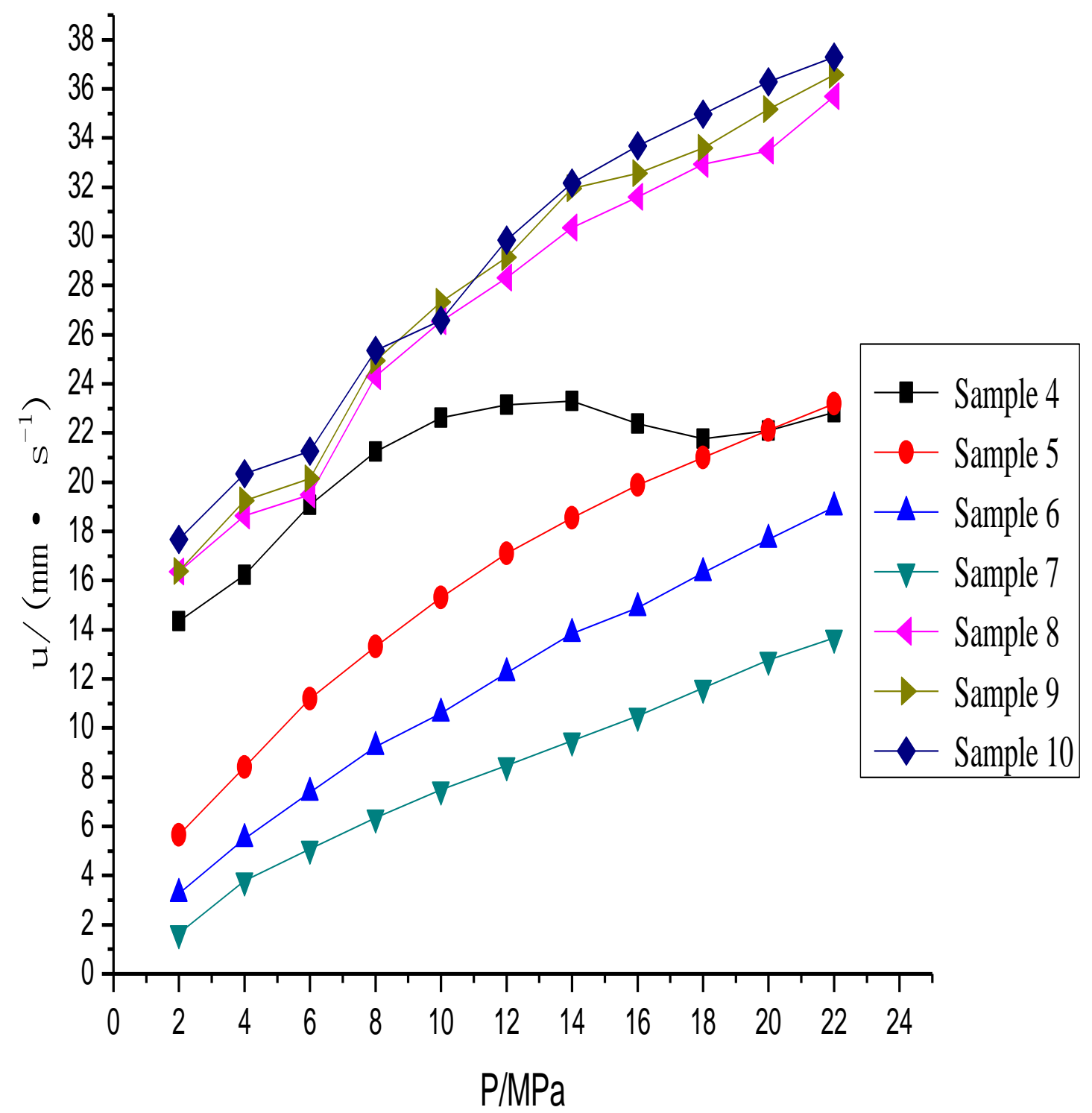

Fig.3 Effects of nm-Al and nm-CB with Different Contents on Combustion Properties of DB Propellant

\section{Effect of nm-DPT, nm-CB and Common Catalyst on Combustion Properties of Al-CMDB} Propellant

Al-CMDB propellant has many advantages such as higher power than DB propellant, good quality consistency, adjustable burning rate and pressure exponent, so Al-CMDB propellants were applied in engine of tactical missile widely. But the burning rate of Al-CMDB propellant was not high enough so the application was limited. In this work, the effects of nm-DPT, nm-CB and common catalyst on propellant's combustion properties were investigated. The results were shown in Fig.4. 


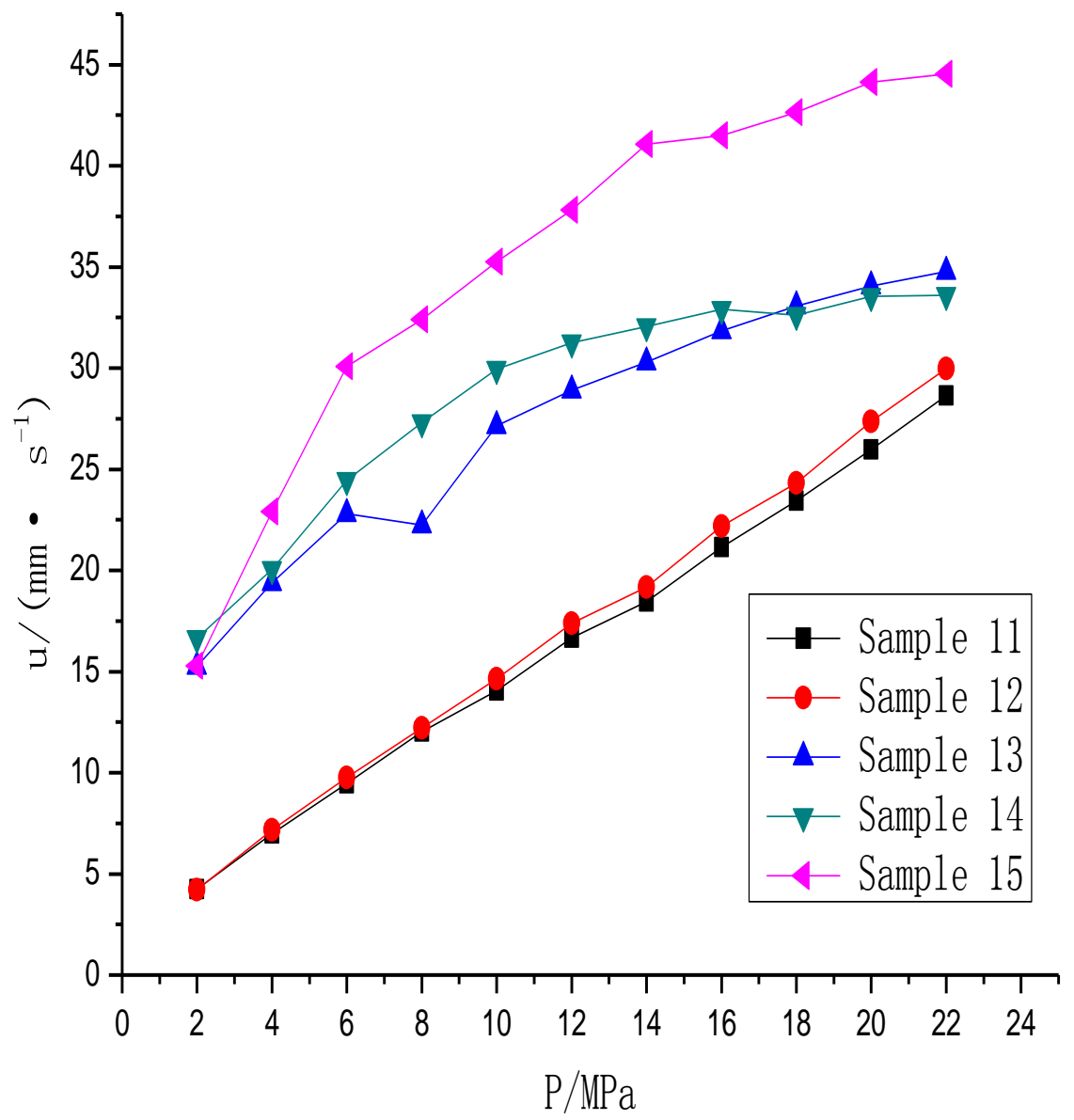

Fig.4 Effects of nm-DPT, nm-CB and Common Catalyst on Combustion Properties of Al-CMDB Propellants

As shown in Fig4, adding 1.0\% nm-DPT could increase the burning rate of Al-CMDB propellant without common catalyst in the zone of $4 \sim 22 \mathrm{MPa}$ by $0.2 \sim 1.0 \mathrm{~mm} / \mathrm{s}$, and increase the pressure exponent in the zone of 2 22MPa from 0.79 to 0.81 .This showed that the effects of nm-DPT on combustion properties of propellants without common catalyst were little.

Adding $0.7 \% \mathrm{~nm}$-DPT could increase the burning rate of Al-CMDB propellant with common catalyst in the zone of $2 \sim 16 \mathrm{MPa}$ and reduce the burning rate in the zone of $18 \sim 22 \mathrm{MPa}$, so the pressure exponent between 8 22MPa reduced evidently from 0.37 to 0.19 , showing a wide plateau zone. Adding more $0.3 \% \mathrm{~nm}-\mathrm{CB}$ could increase the burning rate in the zone of $6 \sim 22 \mathrm{MPa}$ by $6 \sim 11 \mathrm{~mm} / \mathrm{s}$.

Comparing formulation 11, 12, 13 with 14, we could find the nm-DPT has little effects on Al-CMDB propellant without common catalyst, but has great effects on Al-CMDB propellant with common $\mathrm{Pb}-\mathrm{Cu}-\mathrm{C}$ catalyst including increasing the burning rate at the low pressures and reducing the pressure exponents.

Comparing formulation 14 with 15, we could see adding nm-CB or nm-DPT can increase the burning rate of $\mathrm{Al}-\mathrm{CMDB}$ propellant with common $\mathrm{Pb}-\mathrm{Cu}-\mathrm{C}$ catalyst and nm-DPT greatly.

\section{Effects of nm-DPT, nm-CB and Common Catalyst on Combustion Properties of RDX-CMDB Propellant}

RDX-CMDB propellant has many advantages such as good quality consistency,low signature and adjustable burning rate and pressure exponent so RDX-CMDB propellant was applied in many 
model weapons. But their burning rates need to be increased. This paper studied the effect on nm-DPT, nm-CB and common catalyst on RDX-CMDB propellant combustion properties. The results were shown in Fig.5.

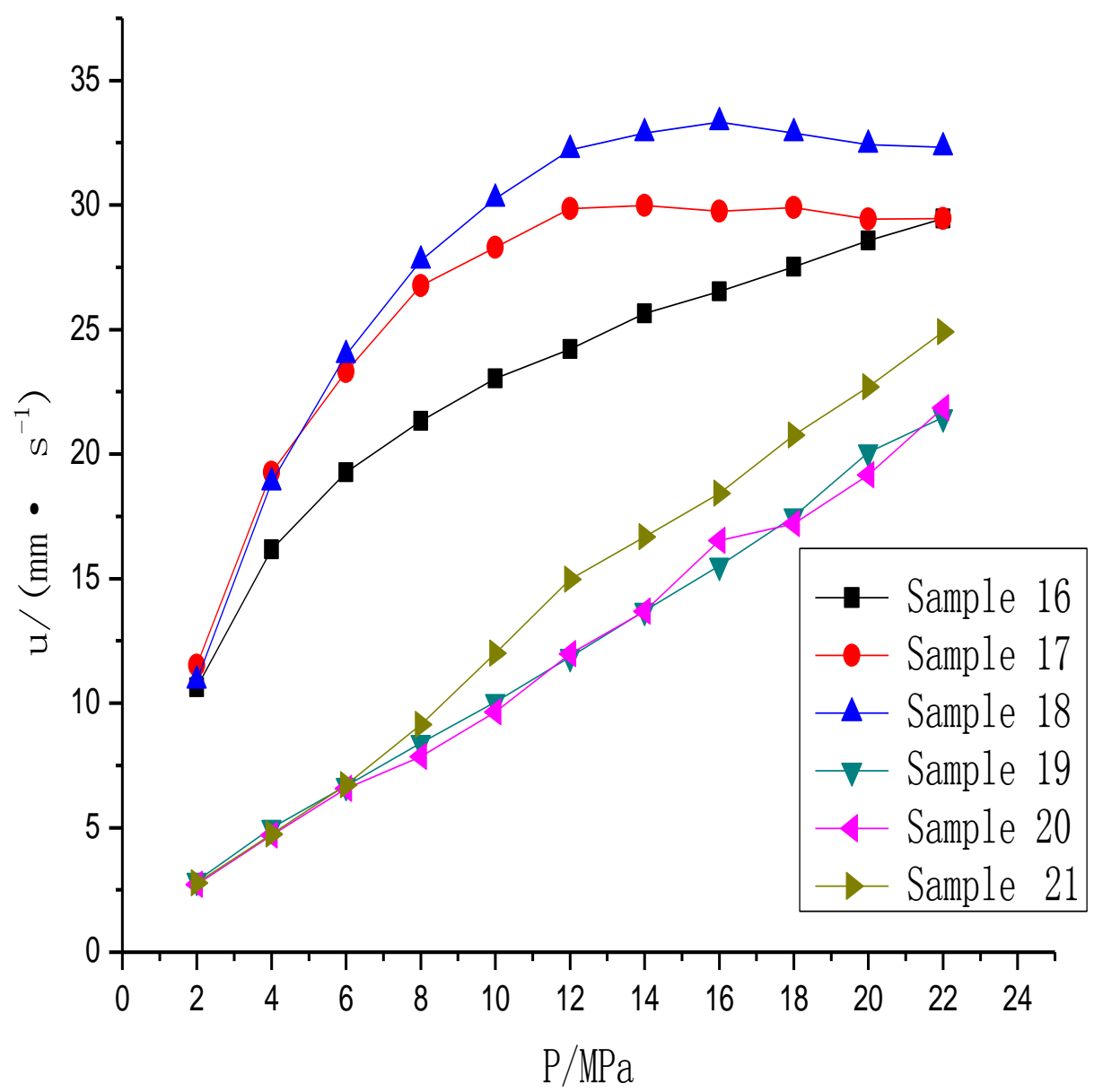

Fig.5 Effects of nm-DPT, nm-CB and Common Catalyst on Combustion Properties of RDX-CMDB Propellant

As shown in Fig.5,the burning rate of RDX-CMDB propellant containing common catalyst would be increased by about $3.1 \sim 5.6 \mathrm{~mm} / \mathrm{s}$ at $4 \sim 16 \mathrm{MPa}$ and about $0 \sim 2.4 \mathrm{~mm} / \mathrm{s}$ at $18 \sim 22 \mathrm{MPa}$, so that the pressure exponent reduce to 0 or much little, showing mesa-burning behavior by adding nm-DPT.

Adding nm-CB to the propellant containing common catalyst and nm-DPT would increase the burning rate by $0.6 \sim 3.6 \mathrm{~mm} / \mathrm{s}$ at $6 \sim 22 \mathrm{MPa}$ and more at $14 \sim 16 \mathrm{MPa}$, so the pressure exponent increased to 0.14 at $8 \sim 22 \mathrm{MPa}$, but reduced to -0.10 in the high pressures of $16 \sim 22 \mathrm{MPa}$.

Adding nm-DPT and nm-CB to the propellant without common catalyst leads to a stepwise increase of the pressure exponent. The burning rate changed a little and the pressure exponent increased a little if adding nm-DPT into propellant. Adding nm-CB to the propellant with nm-DPT would enable the burning rate in the low pressure zone to rise a little but much bigger in the high pressure zone, so the pressure exponent increased (from 0.87 to 0.95 ).

It was concluded that nm-DPT and nm-CB were useful burning catalysts; they could enhance the burning rates and reduce the exponents of propellant with other catalysts. If just adding nm-DPT or nm-CB only into propellant without other catalyst, the effects was little. So adding nm-DPT, $\mathrm{nm}-\mathrm{CB}$ and other catalyst together was a valuable way to enhance the burning properties of DB or 
CMDB propellants.

\section{Conclusions}

(1) The burning rates of DB propellants would reduce and the pressure exponent would increase by adding nm-Al. The burning rates of DB propellants would increase a little and the pressure exponent would not change by adding nm-CB to DB propellant. The burning rate of DB propellant would increase to $40 \mathrm{~mm} / \mathrm{s}$ at $14 \mathrm{MPa}$ and exceed $44 \mathrm{~mm} / \mathrm{s}$ at $20 \mathrm{MPa}$.

(2) Adding nm-DPT made the Al-CMDB propellant including 5.5\% Al powder result in plateau-burning effect at $8 \sim 22 \mathrm{MPa}$, and the burning rate at $10 \mathrm{MPa}$ exceed $29 \mathrm{~mm} / \mathrm{s}$. If adding $\mathrm{nm}-\mathrm{DPT}$ and nm-CB to propellant, the burning rate would increase obviously, exceed $35 \mathrm{~mm} / \mathrm{s}$ at $10 \mathrm{MPa}$ and $40 \mathrm{~mm} / \mathrm{s}$ at $14 \mathrm{MPa}$.

(3) Adding nm-DPT made the RDX-CMDB propellant with $24 \%$ RDX result in mesa-burning effect at $12 \sim 22 \mathrm{MPa}$,and the burning rate at $10 \mathrm{MPa}$ would exceed $28 \mathrm{~mm} / \mathrm{s}$. Addition of $\mathrm{nm}-\mathrm{CB}$ to the propellant with nm-DPT would lead to the ulteriorly increased burning rate ,exceed $30 \mathrm{~mm} / \mathrm{s}$ at $10 \mathrm{Mpa}$ and the pressure exponent would be -0.10 .

\section{Acknowledgement}

1) Project Supported: National Natural Science Foundation of China (21241003 and 20803058)

2) Biography: YUAN Zhi-feng (1980- ), male, bachelor, Major in energetic materials

3) Corresponding Author: ZHAO Feng-qi, (1963- ), male, researcher, Major in energetic marerials

\section{References}

[1] ZHAO Feng-qi, QIN Guang-ming, CAI Bin-yuan. Research status and development trends of nmmeter materials in the application of propellants and explosives, J. Chinese Journal of Explosives and Propellants, 2001, 24(4):61-65.

[2] Sharma J, Wilmot G B, Compolattaro A A et al.XPS study of condensed phase combustion in double base rocket propellant with and without lead salt-burning rate modified, J. Combustion and Flame, 1991, 81:416 426.

[3] HONG Wei-liang, ZHAO Feng-qi, LIU Jian-hong, et al. Synthesis of nm meter PbO,Bi2O3 and their effect on burning propeties of proellants, J. Chinese Journal of Explosives and Propellants, 2001, 24(3):7-9.

[4] Tombler T W, Zhou C M, Alexsetev L, et al. Reversible eletromechanical characteristics of carbon nano tubes under local-probe manipulation, J. Nature, 2000, 405:769-772.

[5] ZHANG Xiao-hong, LONG Cun, WANG Tie-cheng, et al. Study on effects of nm-PbO on the Combustion Properties of Double-base Propellant, J. Chinese Journal of Explosives and Propellants, 2002, 25(2):39-41.

[6] ZHAO Feng-qi, HONG Wei-liang, CHENG Pei, et al. Effect of nm-catalysts on the combustion properties of DB/RDX-CMDB propellants, J. Chinese Journal of Explosives and Propellants, 2004, 27(3):13-16.

[7] LIU Hai-Fei, WANG Meng-yu, JIA Xian-shang, et al. Synthesis of nm meter powder, J. Mining And Metallourgy, 2004, 13(3):65-67.

[8] PANG Wei-qiang, ZHANG Jiao-qiang, ZHU Feng, et al. Reseach of application of a new-type of nmmeter materials in solid propellants, J. Fiber Composites. 2005, (1):12-15. 
[9] XIA Qiang, LI Shu-fen, WANG Gui-lan, et al. Study on effects of superfine aluminum powder on the combustion properties of AP/HTPB propellant, J. Journal of Solid Rocket Technology, 1994,(4):35-42.

[10] CHENG Xue-li, WANG Yin, WANG Hong, et al. Effects of aluminum powder content and granularity on characteristics of CMDB propellant, J. Chinese Journal of Energetic Materials, 16(6):721-723.

[11] CHU Guang, TANG Yong-jian, CHU Shi-jin, et al. Characterization of structure and properties of Al nmparticles, J. Chinese Journal of Energetic Materials, 2006, 14(3):22-230.

[12] LI Ying,SONG Wu-lin, XIE Chang-sheng, et al. Progress in the application of nm aluminum powder in solid propellants, J. Acta Armamentarii, 2005, 26(1):121-125.

[13] YUAN Zhi-feng, WANG Jiang-ning, ZHANG Chao, et al. Effect of nm-materialson combustion properties of DB and CMDB propellants, J. Chinese Journal of Explosives and Propellants, 2013, 36(3):69-72.

[14] ZHANG Wei, XIE Wu-xi, FAN Xue-zhong, et al. Influence of nanometer aluminium powder to burning property of smokeless NEPE propellant, $\mathrm{C}$. The 13th China International Conference on NanoScience and Technology, Chengdu. 2014, 10, 26-30.

[15] DENG Kang-qing, WANG Guang-tian, WANG Guang-lan. The Characteristics and Model for Superfine Aiuminum Powder Combustion, J. Journal of Solid Rocket Technology, 1996, 19(1):28-37.

[16] YAO Er-gang, ZHAO Feng-qi, HAO Hai-xia, et al. Preparation of Aluminum anopowders Coated with Perfluorotetradecanoic Acid and Its Ignition and Combustion Characteristics, J. Chinese Journal of Explosives and Propellants , 2012, 35(6):70-75. 